\title{
C)
}

\section{Linguística documental e semiótica documental: percurso espanhol}

\author{
Alexandre Robson Martines \\ Doutorando; Universidade Estadual Paulista, Marília/SP, Brasil; \\ alexandre.martines@unesp.br; ORCID: https://orcid.org/0000-0002-4524-0978 \\ Carlos Cândido de Almeida \\ Pós-doutor; Universidade Estadual Paulista, Marília/SP, Brasil; \\ carlos.c.almeida@unesp.br; ORCID: https://orcid.org/0000-0002-8552-1029
}

\begin{abstract}
Resumo: A proposta desta pesquisa é analisar o processo epistemológico da Linguística Documental, bem como a Semiótica Documental na Espanha. Somado a isso, também deseja analisar a relação dessas disciplinas com a Documentação desenvolvida na Espanha. Outrossim, estabelecer breves relações com as teorias que atuam como base da Linguística Documental, no caso a Linguística Estrutural e da Semiótica Documental, por sua vez, a Semiótica. Para tanto, aplicou-se uma metodologia de natureza qualitativa, tipo descritiva, de caráter exploratória. Trata-se de abordagem teórico-bibliográfica, com o propósito crítico e reflexivo acerca das disciplinas Linguística Documental e Semiótica Documental, bem como acerca da Linguística Estrutural e Semiótica. Desse modo, há um processo metalinguístico nos procedimentos que envolvem a interpretação da informação e sua organização em conceitos e na representação do documento, por via de uma tradução de conceitos responsáveis por representar a informação documental, já que essa informação é produzida em linguagem natural, por conseguinte traduzida, em procedimentos metalinguísticos, para a linguagem documental especializada. Portanto, os estudos que exploram a Organização do Conhecimento e a Ciência da Documentação estão alinhados à importância da linguagem no processo de tratamento documental. Sendo assim, a Linguística possibilita extrair do documento informações que estão subentendidas e inscritas em seus aspectos dialógicos, em uma perspectiva intertextual, o chamado signo documental, a mesma medida, a Semiótica peirceana possibilita tratar a semiose documental.
\end{abstract}

Palavras-chave: Linguística Documental; Semiótica Documental; Ciência da Documentação; Documentação espanhola

\section{Introdução}

O tratamento documental, conjunto de procedimentos e operações técnicas que incluem análise, avaliação, extração, classificação, descrição, representação, 
síntese e indexação de conceitos presentes em um documento, caracterizando a gestão documental, é um procedimento importante para a extração da informação presente no documento e, assim, possibilitar a análise de seu conteúdo a fim de representar os conceitos que exprimem o conhecimento constituído.

Essa representação se configura a partir da leitura e interpretação do documento original e, posteriormente, deve-se elaborar um documento secundário - documentos elaborados para representar e organizar as informações do documento original, utilizando-se de terminologia adequada, conjunto de léxico de especialidade, o qual se estabelece de modo radical por motivos basicamente funcionais, caracterizando-se em linguagem documental, linguagem específica para a representação das informações documentais à base de normalização e pertinente a um domínio científico.

Após as teorias desenvolvidas por P. Otlet, na década de 1930, sobre a Documentação - ciência destinada aos estudos acerca do tratamento material do objeto documento -, as preocupações acerca do tratamento documental chegaram à Espanha, através dos estudos de Lasso de la Vega (1935). Inserida no processo de análise e tratamento documental, a linguagem também foi ponto importante nas pesquisas e estudos espanhóis. Diante disso, Garcia Gutiérrez (1984, 1989), inspirado nos estudos de López Yepes, em 1978, propõe uma disciplina específica para tratar a linguagem especializada: a Linguística Documental, disciplina destinada a tratar adequadamente as informações contidas no documento.

Nessa perspectiva, os estudos sobre linguagem, os quais perpassavam pelos estudos sobre a análise documental - técnica importante de tratamento da informação do documento, que tem como princípio a investigação a fim de extrair da informação coletada conceitos para garantir o armazenamento, a representação e a indexação dos documentos - ganharam importância.

Assim, sendo direcionados pelas indicações de García Gutiérrez, esses estudos estabelecem a relação interdisciplinar com outra área, cujo objeto de estudo é a linguagem: a Linguística, campo do conhecimento que estuda a linguagem humana. No caso, trata-se da Linguística Estrutural - área que se 
propõe a investigar elementos básicos da linguagem, como o sistema de signos, com abordagem próxima ao proposto por F. Saussure, em 1916. Diante disso, a Linguística Documental ganha dinamismo ao ser aplicada com a finalidade de garantir extração adequada das informações e a elaboração de uma representação que lhe garantisse a recuperação de seu conteúdo.

Ademais, Izquierdo Arroyo (1990), diante da necessidade de elaborar um currículo acadêmico a fim de estruturar o ensino da Linguística Documental, com a finalidade de aprimorar os estudos sobre a análise de conteúdo e metodologia de resumo científico apresenta um estudo que dialogava com as perspectivas da Semiótica, cujo objeto de estudo são os signos e, consequentemente, os fenômenos que envolvem a semiose, desenvolvidas por C. S. Peirce (2017) e C. W. Morris (1976).

Dessa forma, Izquierdo Arroyo defende a necessidade de se estudar a semiose documental, que se caracteriza pela inovação de sentido nas informações presentes nos documentos no ato de tradução documental, ou seja, presentes na elaboração do documento secundário, como resultado da prática semiótica para garantir a representação adequada das informações presentes nos documentos.

Diante desses fatos, foi objetivo dessa pesquisa analisar o processo epistemológico e refletir sobre sua configuração na consolidação da Linguística Documental, bem como a Semiótica Documental na Espanha. Somado a isso, também se interessa pela análise da relação dessas disciplinas com a Documentação desenvolvida na Espanha. Outrossim, por fim, também se torna válido estabelecer breves relações com as teorias que atuam como base para a consolidação da Linguística Documental, no caso a Linguística Estrutural e da Semiótica Documental, por sua vez, a Semiótica.

Essa temática se justifica, pois, embora seu desenvolvimento tenha ocorrido na Espanha, há correntes no Brasil, como por exemplo o Grupo TEMMA - ECA/USP, que por mais que tenha desenvolvido seus trabalhos sob a influência da corrente francesa, em que se destaca o trabalho encabeçado por J-C Gardin, desenvolvido em 1966, também analisou com propriedade as contribuições espanholas, como pode ser recuperado nos trabalhos de Lara (2004, 2009, 2011, 2015); Tálamo; Lara (2006); Lara; Tálamo (2007), que 
evidenciam um dialogismo com seus fundamentos teóricos e práticos. Dessa maneira, esta pesquisa corrobora o entendimento e a sistematização dessas disciplinas, além de esclarecer sobre a aplicabilidade de seus conceitos e fundamentos teóricos e práticos.

Sendo assim, aplica-se uma metodologia de natureza qualitativa, voltada à descrição dos processos epistemológicos, bem como a descrição dos principais elementos que constituíra cada disciplina. Também se caracteriza por ser exploratória, já que há a análise das disciplinas em questão: Linguística Documental e Semiótica Documental, somado à análise dos fundamentos de suas respectivas bases teóricas: Linguística Estrutural e Semiótica.

Ademais, trata-se de abordagem teórico-bibliográfica, com base em uma revisão narrativa da literatura, através de periódicos, dissertações e teses recuperados de bases de dados como Brapci, Dialnet, Google Scholar, em idioma português, espanhol e inglês, sem demarcação específica de dada de publicação, sendo a recuperação direcionada pela temática abordada, além de livros especializados no assunto, com o propósito crítico e reflexivo acerca das disciplinas Linguística Documental e Semiótica Documental, bem como acerca da Linguística Estrutural e Semiótica.

Para tal configuração da abordagem, analisaram-se as teorias sobre Documentação, cunhadas por P. Otlet, em 1934, assim como as inovações de Lasso de la Vega, em 1935, somado às contribuições de López Yepes, apresentadas em 1978. Além disso, também foram analisados os estudos sobre Linguística Documental, propostos por García Gutiérrez (1984, 1989), além da sua base teórica, a Linguística Estrutural, fundamentada por F. Saussure, em 1916 e L. Hjelmslev, a partir de 1943. Por fim, as pesquisas e contribuições de Izquierdo Arroyo (1990) sobre a Semiótica Documental, bem como os fundamentos de sua base teórica, a Semiótica, proposta por C. S. Peirce, desenvolvidas a partir de 1867 e C. W. Morris (1976).

Nessa perspectiva, espera-se contribuir com avanços acerca da Linguística Documental e da Semiótica Documental referente à sua compreensão epistemológica, assim como suas contribuições para o tratamento e análise do documento, além de proporcionar mecanismos para uma melhor representação da informação documental, já que essas teorias estão direcionadas 
à interpretação, ao tratamento do signo e de sua significação, assim oferecendo ao profissional responsável pela representação procedimentos coerentes para a execução de sua atividade laboral. Ademais, espera-se contribuir com a difusão dos conhecimentos sobre as disciplinas mencionadas, visto que os estudos sobre sua configuração e inovações são bem restritos no Brasil.

\section{Documentação}

A Documentação, como ciência, foi fundamental como contexto motivador para o surgimento dos estudos acerca da Linguística Documental, propostos por García Gutiérrez (1984), já que o desenvolvimento de pesquisas sobre a Documentação foi promissor na Espanha, devido às preocupações que circundavam o tratamento do documento.

A ciência da Documentação foi proposta por P. Otlet, em 1934 e ganhou importância diante dos apontamentos do autor belga, juntamente com Henri La Fontaine (1934), acerca das propostas que envolvem o tratamento do documento, visto que o documento possui papel importante na história da humanidade, seja para registrar as invenções, as inovações e, assim, a evolução do pensamento, seja para provar e legitimar o conhecimento, seja para compreender esse conhecimento e aprender com as próprias inovações, ou as inovações dos antepassados.

A influência de Otlet e da Documentação foi impactante na Espanha, pois estava direcionada à constituição das "ciências do livro", de onde surge "[...] em última instância a reflexão que dispara sua incursão no futuro: as transformações do documento e as técnicas adequadas para ele, fazem necessária um corpo de conhecimento.” (IZQUIERDO ARROYO, 1994, p. 24, tradução nossa).

Consequentemente, seus argumentos sobre uma metadocumentação ou documentação pura foram responsáveis para promover, na Espanha, estudos e pesquisas para entender os procedimentos da ciência, assim como estabelecer essa prática como disciplina a fim de que houvesse a formação adequada de profissionais responsáveis pela análise documental, sua representação e indexação (IZQUIERDO ARROYO, 1994). 
Essa prática promoveu a necessidade de debater sobre a linguagem especializada aplicada para promover a representação, consequentemente originando os estudos acerca da contribuição da Linguística, assim estruturando os princípios da Linguística Documental, posteriormente, da Semiótica Documental.

Diante disso, o objetivo desta seção é analisar os conceitos sobre documento e observar as contribuições de Otlet (2018), Briet (2016) para a consolidação da ciência da Documentação. Diante disso, analisar a influência da ciência no cenário espanhol e o modo como se estabeleceram os princípios conceituais que efetivam a Documentação como ciência e sua caracterização como disciplina para proporcionar práticas de análise e tratamento documental, bem como a extração conceitual, a representação, o armazenamento, a indexação e a recuperação da informação presente no documento. Para tanto, tem-se como base os estudos de Lasso de la Vega (1935), López Yepes (1995) e Izquierdo Arroyo (1990, 1994, 1995).

Nesta perspectiva, é válido destacar a importância da Documentação no estudo do documento, já que diversas atividades profissionais, como a História, a Literatura, a Administração, o universo jurídico etc. dependem dos fluxos informacionais presentes tanto em documentos históricos, como também na produção contínua de documentação para validar as ações humanas.

O documento registra a história, resgata a informação, atualiza o conhecimento. As informações presentes em sua composição possuem caráter dinâmico de significação devido à interação, ao manuseio e à interpretação. $\mathrm{O}$ documento, sendo físico ou digital, não é estático. Seu conteúdo se atualiza sempre que é posto em curso significativo frente a um discurso.

Sendo assim, o documento tem a função de informar algo (BUCKLAND, 1997, 2014, 2015, 2018), ou ainda deve ser visto como instrumento capaz de materializar a informação, atuando como material de suporte, além de conteúdo comunicacional (ESTIVALS, 1981, 2010; MEYRIAT, 1981, 2016; RAYWARD, 1994; DAY, 2016; FAYET-SCRIBE, 2016; ORTEGA; SALDANHA, 2019).

Ainda pode ser classificado como "produto de uma vontade", além de ser “[...] um objeto que suporta a informação, que serve para comunicar e que é 
durável (a comunicação pode, assim, ser repetida).” (MEYRIAT, 2016, p. 241), além de não ser neutro, tampouco inócuo, de fato trata-se de escolhas que sistematizam um todo, já que se trata de um conjunto de dados do passado, em que há uma preferência de um documento por outros, assim "[...] atribuindo-lhe um valor de testemunho que, pelo menos em parte [...]", visto que depende da posição social de quem o seleciona, como ainda é decorrente de uma organização mental (LE GOFF, 1994, p. 472).

Dessa forma, “[...] o documento tornou-se recurso necessário e indispensável para os pesquisadores que tinham a obrigação de apresentar as suas fontes de informação como recurso para garantir confiabilidade aos trabalhos por eles produzidos.” (MURGUIA, 2011, p. 43).

Ademais, Otlet (2018, p. 11) definiu que "Livro (bíblion, documento ou grama) é o termo convencional aqui empregado para designar toda espécie de documento.", portanto quando o autor belga propõe seu tratado sobre documentação, idealizando o Mondaneum, em 1924, atrelado ao seu Princípio Monográfico para tratamento documental, além de uma linguagem documental específica, a Classificação Decimal Universal (CDU), a fim de estabelecer o tratamento adequado, através de fichas padronizadas, houve também a proposta fecunda do livro universal para a difusão do conhecimento.

Assim, o conceito de documento para Otlet "Abrange não apenas o livro propriamente dito, manuscrito ou impresso, mas também revistas, jornais, textos escritos e reproduções gráficas de qualquer espécie, desenho, gravuras, mapas, esquemas, diagramas, fotografias etc.”(OTLET, 2018, p. 11).

Outrossim, é importante destacar as inovações propostas por S. Briet, em 1951, visto que ao documento é atribuída uma perspectiva de função indicial, ou seja, o documento é "[...] todo indício, concreto ou simbólico, com a finalidade de representar, reconstruir ou provar um fenômeno físico ou intelectual." (BRIET, 2016, p. 1), em que a prática da Documentação se consiste na elaboração de um documento secundário para registrar as informações do documento original. Além disso, tem-se como definição de documento a ideia de que é "[...] toda base de conhecimento fixada materialmente e suscetível de ser utilizada para consulta, estudo ou prova.” (BRIET, 2016, p. 1). 
Para exemplificação de sua definição de documento, Briet menciona a descoberta de uma nova espécie de um antílope e as etapas de divulgação da informação: "o comunicado para a imprensa", "o animal enjaulado", depois morto, "empalhado e conservado no museu", assim "os documentos são reproduzidos", “depois selecionados, resumidos, descritos, traduzidos" (BRIET, 2016, p. 2). Dessa forma, “O antílope catalogado é um documento primário e os demais são documentos secundários ou derivados.” (BRIET, 2016, p. 2).

Portanto, diante da concepção de que qualquer coisa pode ser um documento, conquanto se prove algo, além do princípio de universalidade, a Documentação ganha importância em um cenário direcionado às atividades de tratamento do documento e da elaboração de documentos capazes de representação da informação extraída do original a fim de organizar o conhecimento veiculado.

Desse modo, reconhece-se que os estudos acerca do documento se desenvolveram a partir das propostas de P. Otlet e os avanços apresentados por S. Briet colaboraram para o avanço de técnicas sobre a representação e teorias debatendo sobre a organização, as quais na Espanha foram aproximadas de estudos direcionados à aplicação da linguagem para efetuar uma representação e organização mais eficiente.

Sendo assim, esta seção apresentou algumas considerações que corroboraram a análise da Documentação na Espanha e, dessa forma, compreender às premissas que levaram os estudos a discutirem o papel da linguagem na representação da informação e do conhecimento, estabelecendo, assim, o surgimento da Linguística Documental e, posteriormente, da Semiótica Documental. 


\section{Documentação na Espanha}

A Documentação na Espanha ganha destaque e importância devido ao desenvolvimento desta área científica na Europa. Os trabalhos apresentados por P. Otlet (1934) foram seguidos por tratadistas espanhóis, como destaque tem-se Lasso de la Vega (1935), sendo este responsável pela introdução dos estudos nas pesquisas espanholas. Além disso, o interesse da indústria sobre a organização da informação e as estratégias informacionais contribuíram para o avanço da área.

Dessa forma, torna-se foco da discussão a análise da evolução da Documentação na Espanha, assim como o seu percurso epistemológico. Dessa maneira, compreender a perspectiva espanhola na contribuição do âmbito da Documentação e os avanços dessa área para a análise e tratamento dos documentos, como ainda, através desses estudos, acompanhar como a linguagem ganha importância nesse cenário.

As preocupações direcionadas ao tratamento do documento, na Espanha, são fomentadas pelas considerações da escola norte-americana, denominada Information Science; da escola soviética, chamada de Informatika; por fim, a influência das produções belga e alemã. Efetivamente, e a partir do contato de Lasso de la Vega com as produções de P. Otlet que os estudos acerca do documento na Espanha ganham destaque.

Devido ao impacto das teorias produzidas na Europa e nos Estados Unidos, a Espanha passa a se preocupar com procedimentos e com teorias. Ao mesmo tempo em que essa preocupação visava às práticas técnicas e profissionais, há também os debates de questões terminológicas, assim como procedimentos burocráticos para transformar e adequar os conceitos científicos e procedimentais em princípios práticos de uma disciplina.

Sobre as questões terminológicas, havia o questionamento sobre o termo adequado à identificação da ciência na Espanha, que melhor se ajustaria à tradução para o espanhol, além de esclarecer as marcas significativas em cada terminologia utilizada, pois evidenciaria as características epistemológicas de seu país-origem, responsável por definir as matrizes de diferenciação conceitual. Assim, a discussão acerca da terminologia visava a compreender quais fundamentos deveriam ser absorvidos pela escola espanhola. 
Frente aos problemas terminológicos relacionados à Documentação, a Espanha optou por seguir os passos de Otlet, somado às definiçõos e às propostas que surgiram em vários estudos desenvolvidos por países socialistas, Estados Unidos e Alemanha, respectivamente Informatika, Information Science, Informacion - und Dokumentationswissenschaft (LÓPEZ YEPES, 1995, tradução nossa), que alinhavam o desenvolvimento técnico da Documentação com as preocupações epistemológicas da Ciência da Informação.

Sendo assim, a construção epistemológica da Documentação na Espanha é conduzida pela produção de P. Otlet e Henri La Fontaine, destacando o Tratado da Documentação de 1934 e suas perspectivas acerca da problemática, aplicando-se uma estratégia inovadora com foco na "[...] organização dos conhecimentos e a busca permanente de uma síntese que permitia conhecer a formação e o crescimento dos conceitos." (OTLET, 2018). Nessa perspectiva, Otlet encanta a escola espanhola com a proposta de "organização lógica e racional do todo", através da "[...] investigação de fatos concretos, como ainda um complexo mundo de ideias e princípios.” (LÓPEZ YEPES, 1995, p. 65, tradução nossa).

Lasso de la Vega é responsável, portanto, pela introdução dos estudos de Otlet na Espanha. Assim, é visto como o "[...] introdutor da Ciência da Documentação na Espanha, verdadeiro arquiteto de seu progresso e desenvolvimento [...]" (LÓPEZ YEPES; ROS GARCÍA, 1993, p. 21, tradução nossa). Dessa forma, através de seu Manual de Documentación, escrito em 1947, são introduzidas na Espanha a "[...] Classificação Decimal Universal, a propagação do conceito Documentação, propriamente dito, e a aplicação da Documentação a campos concretos do saber como o Direito." (LÓPEZ YEPES; ROS GARCÍA, 1993, p. 21, tradução nossa).

Assim, Lasso de la Veja, através das considerações de L. de Gregori, define que Documentação "[...] é a técnica de escolher e organizar, por meios de signos de qualquer espécie (escrituras, imagens, esquemas, símbolos etc.) [...]" (LÓPEZ YEPES; ROS GRACÍA, 1993, p. 23, tradução nossa). Além de estabelecer a relação das técnicas profissionais com as necessidades de mercado, visto que as preocupações com as informações selecionadas e os procedimentos de recuperação que sejam mais rápidos e eficientes ganham destaque no âmbito 
informacional, devido às necessidades mercadológicas e aos interesses do ramo industrial.

Nessa perspectiva, pode-se entender que o desenvolvimento da Documentação na Espanha deve-se, primordialmente, aos interesses relacionados à produção informacional direcionada à indústria, "O movimento a favor da Documentação nasceu como consequência da investigação praticada nos meios industriais [...]", esse fato teve contribuição decisiva para que houvesse um movimento científico a favor do desenvolvimento teórico e investigação sobre a Documentação, já que os interesses econômico-industriais “[...] têm sentido muito rápido a necessidade de se informarem com detalhes precisos sobre os progressos realizados nos seus respectivos campos [...]" (LÓPEZ YEPES; ROS GARCÍA, 1993, p. 25, tradução nossa).

Definitivamente, a sociedade industrial foi a grande responsável para que a Espanha se preocupasse em explorar a estrutura e os mecanismos da Documentação para incrementar um sistema de gestão de informação, pois a informação se tornou "recurso chave para as organizações" (LÓPEZ YEPES, 1995, p. 192, tradução nossa). Assim a Documentação assume um papel importante, juntamente com a tecnologia, devido ao propósito de “[...] centralizar e processar todos os dados necessários para o funcionamento organizacional e ajudar na tomada das decisões.” (LÓPEZ YEPES, 1995, p. 192, tradução nossa).

Portanto, é válido enfatizar que além da preocupação científica, a Documentação também está incumbida de responder às exigências dos setores econômico e industrial, visto que se desenvolveram pesquisas e estudos para aprimorar a investigação das informações e, assim, pensar de forma estratégica como aplicar o fluxo informacional mediante às necessidades das organizações.

Dessa forma, define-se na Espanha que "[...] documentar é reunir, classificar e distribuir documentos de todo tipo em todos os domínios de atividade humana." (LÓPEZ YEPES, 1995, p. 129, tradução nossa). Concomitantemente, define-se também que a Documentação “[...] se ocupa de materiais nas bibliotecas, para cujo tratamento as normas biblioteconômicas não estavam, a princípio, preparadas.” (LÓPEZ YEPES, 1995, p. 129, tradução nossa). 
Sendo assim, a tarefa da Documentação caracteriza-se por ser uma tarefa de informação, portanto há a preocupação direcionada à análise documental, por isso as contribuições da linguagem para seu tratamento é alvo de estudos de García Gutiérrez (1984) e Izquierdo Arroyo (1990). Assim, para García Gutiérrez "documentação é informação", consequentemente a documentação está “condicionada à linguagem” (GARCÍA GUTIÉRREZ, 1984, p. 75, tradução nossa). Ademais, no avanço desses estudos, são os professores Segredo e Izquierdo Arroyo, em 1983, que aplicam o conceito lógico-linguístico, ou seja, trazem aspectos semióticos para o tratamento documental.

Sendo assim, a Ciência da Documentação, na Espanha, tem seus estudos iniciados em 1978 e, a partir disso, ganha destaque nas preocupações referentes ao tratamento do documento. Esses estudos exploraram as discussões na Europa, nas linhas soviética e alemã, assim como os estudos nos Estados Unidos. A somativa dessas teorias, mais as propostas de Otlet direcionaram os estudos de Lasso de la Vega. Com isso, os estudos espanhóis trouxeram respostas às necessidades científicas e do mercado.

O cenário científico se desenvolveu sob as discussões que envolveram a terminologia, os conceitos como ciência, além do desenvolvimento das técnicas e procedimentos que constituíram a Documentação também como disciplina na Espanha. Nessa linha, é preciso destacar os trabalhos fundamentais, que serviram de estruturação para o desenvolvimento da Documentação na Espanha, além de Lasso de la Veja, em 1935, destacam-se Ros García, em 1935, Ortega y Gasset, também em 1935, García Ejarque, em 1943, Teresa María Rovira, em 1963, María del Carmen Pescador del Hoyo, em 1966, J. M. Desantes, em 1970, J. R. Perez Álvares Osorio, em 1976, Ricard Jerez e Amador de los Rios, em 1977.

Assim, é factual a presença nos debates dos tratadistas espanhóis os pensamentos de Mikhailov, Chernyi e Gilyarevskii, os soviéticos por trás dos conceitos de Informatika, assim como Mooers, Taylor, Borko, pesquisadores responsáveis pelo desenvolvimento dos conceitos de Information Science (LÓPEZ YEPES, 1995, tradução nossa).

Diante dessas ações, o tratamento documental torna-se foco de estudos, em busca da extração das informações e sua representação, por isso iniciam-se 
estudos acerca da linguagem, primeiramente nas suas concepções linguísticas e, finalmente, evidenciando os aspectos semióticos.

\section{Linguística documental na Espanha}

Os estudos, na Espanha, sobre a Documentação abriram espaço para que houvesse a preocupação com o tratamento das informações documentais. Sendo assim, surgem estudos que destacam a linguagem nesse processo de tratamento e representação das informações presentes nos documentos.

É, nessa perspectiva, que os estudos iniciados por Lasso de la Veja, em 1935, o qual visava à compreensão das propostas de Otlet, em 1934 e, assim, introduzi-las no cenário espanhol. Somado a isso, López Yepes, em 1978, dialogando com os estudos franceses de J-C. Gardin, em 1966, entende ser importante para a Ciência da Documentação, estudos que viabilizassem o papel da linguagem. Mas foi apenas com García Gutiérrez (1984) que surge uma disciplina destinada ao tratamento da linguagem: a Linguística Documental.

Diante disso, torna-se objetivo desta seção analisar e discutir sobre a fundamentação epistemológica da disciplina Linguística Documental, bem como seus pressupostos teóricos fundados a partir da Linguística Estrutural, além de analisar princípios propostos para representação das informações presentes no documento.

Assim, entende-se que, com os estudos apresentados por García Gutiérrez (1984) e as contribuições e inovações propostas por Izquierdo Arroyo (1990), a Linguística Documental torna-se disciplina, na Espanha, em busca de métodos para tratar adequadamente as informações contidas nos documentos. Portanto, os estudos sobre Linguística Documental surgem no cenário da Documentação e da formação do profissional em tratamento documental, pois se efetiva com a aproximação dos estudos da Documentação aos estudos acerca da linguagem, caracterizando-se, dessa maneira, como estudos interdisciplinares.

Essa relação entre as práticas de tratamento documental e a linguagem necessita da aplicação de uma linguagem especializada, em que sua organização semântica esteja adequada ao campo científico com o qual o documento, informação e conhecimento dialogam. Diante da necessidade de tratar a linguagem aplicada na representação, com eficiência, García Gutiérrez recorre à 
Linguística Estrutural, cujos conceitos provinham das teorias apresentadas por F. Saussure, em 1916.

F. Saussure, em 1916, com a publicação do seu Curso de Linguística, propõe que a Semiologia tinha como objetivo propor algumas discussões, estando elas centradas em dicotomias: langue $\mathrm{x}$ parole; significante $\mathrm{x}$ significado; sincrônico x diacrônico; eixo sintagmático x eixo paradigmático, além das discussões sobre arbitrariedade e convencionalidade. É bem verdade que a contribuição de Saussure para "[...] uma teoria de semiótica foi o projeto de teoria geral para os signos, teoria que ele denominou de Semiologia." (NÖTH, 1996, p. 15).

Para o linguista, a língua é de natureza concreta, assim ele aponta que “Os signos linguísticos, embora psíquicos, não são abstrações, e essas associações são ratificadas pelo consentimento coletivo e possuem sede no cérebro, o que indica que os signos da língua são tangíveis, e a escrita pode fixálos." (SAUSSURE, 2006, p. 23). Tal pensamento de Saussure corrobora a afirmação de que "[...] o significante é imotivado, isto é, arbitrário em relação ao significado, com o qual não possui nenhum laço natural de realidade." (NÖTH, 1996, p. 26).

Desse modo, é válido destacar que essa concepção sobre o signo dialoga com as perspectivas dos pensamentos acerca do monismo filosófico, preso às formas medievais, apresentadas à base de uma idealização platônica defendida por Santo Agostinho (Agostinho de Hipona, 354-430), além das contribuições do mentalismo e nominalismo surgidos com o Racionalismo de Gottfried Wilhelm Leibniz (1646-1716) e ratificado pela fundamentação metafísica do Idealismo, que sistematiza a ascensão do Positivismo no século XIX.

Depois disso, surgiu o Estruturalismo Linguístico. L. Hjelmslev, em 1943, contribui para as teorias da linguagem, oferecendo sua teoria Glossemática, no que tange à concepção do plano da expressão e do plano do conteúdo, assim como suas explanações acerca da forma da expressão e forma do conteúdo, como ainda a substância da forma e a substância do conteúdo. Sob influências aristotélicas, o autor define que Substância é elemento sob o qual se concentra o pensamento e o sentido; Matéria, que evidencia a essência do referente e Forma, que define a estrutura (HJELMSLEV, 2013). 
Essas grandezas - como o autor denomina - relacionadas propõem uma função semiótica. Diante disso, o linguista apresenta uma Semiótica Denotativa e suas relações como as explicações metalinguísticas, assim como a Semiótica Conotativa, já que vai explorar o âmbito da Literatura e da Estética. São as questões metalinguísticas que chamam a atenção de García Gutiérrez e Izquierdo Arroyo para o processo de representação, pois os autores espanhóis defendem que a elaboração de um documento secundário a partir de um documento original viabiliza-se por um procedimento metalinguístico.

A teoria de L. Hjelmslev possui relações diretas com a teoria de F. Saussure, assim pode-se perceber a relação entre Plano da Expressão com o Significante e Plano do Conteúdo com o Significado, porém Hjelmslev (2013, p. 53) defende que "[...] o signo é a expressão de um conteúdo [...]" e não "[...] como um todo formado por uma expressão e um conteúdo.”, como defendia Saussure.

Sobre a necessidade de se estreitar os estudos sobre a Linguística para aprimorar o tratamento da linguagem na análise documental, García Gutiérrez argumenta que "A documentação em seu nível científico, como disciplina que estuda o processo científico-informativo, relaciona-se com a problemática da comunicação, cujo veículo ou meio básico é a linguagem [...]” (GARCÍA GUTIÉRREZ, 1984, p. 137, tradução nossa).

Somado a isso, o autor também aponta que "[...] a Linguística se ocupa do estudo da linguagem como um sistema para comunicar informações, ambas disciplinas, no âmbito de diálogo documental, se fundem constituindo a denominada Linguística Documental [...]", assim constituindo a fusão das duas disciplinas garante o "diálogo documental", para o qual deve haver um “cruzamento dos termos" para denominar a formatação da disciplina Linguística Documental (GARCÍA GUTIÉRREZ, 1984, p. 137, tradução nossa).

Sendo assim, García Gutiérrez (1984, p. 137, tradução nossa) defende o surgimento de uma consciência por parte dos documentalistas sobre a utilização de alguns conceitos e avanços da linguística para tratar da grande quantidade de conteúdos informacionais, por isso a Linguística Documental deve se ocupar da "linguagem dos documentos e, portanto, do diálogo e mensagens documentais". Desse modo, Linguística Documental é vista pelo autor como uma "[...] 
disciplina ligada aos processos informativo-documentais (científicoinformativos e profissionais) que tem por objetivo o estabelecimento de um efetivo controle documental mediante a utilização de mecanismos léxicos." (GARCÍA GUTIÉRREZ, 1984, p. 138, tradução nossa).

Desse modo, García Gutiérrez, em seu livro Linguística Documental: aplicação à documentação da comunicação social (1984), refere-se à Linguagem Documental como "[...] meios de expressão criados por e para o controle dos documentos [...]", já que o autor via a necessidade de controlar os documentos à base da Linguística, pois esta estuda a linguagem humana, ou seja, "[...] todo sistema de signo que expressa ideias através de uma mensagem, ligado a uma atividade humana [...]” (GARCÍA GUTIÉRREZ, 1984, p. 136, tradução nossa).

Consequentemente, as necessidades decorrentes do tratamento do documento, bem como as preocupações com a linguagem aplicada para representar o documento, e as técnicas da análise documental perpassam pela extração da informação, portanto há o cuidado com a linguagem na veiculação da mensagem, assim como a aplicação de uma linguagem documental especializada também é fundamental para a representação do documento, além de garantir sua recuperação.

O controle dos documentos precisava de um trabalho específico com a linguagem, principalmente para estabelecer normas e procedimentos de controle para que a representação fosse eficiente tanto para o armazenamento, quanto para a recuperação, assim a Linguística Documental surge em um cenário extremamente preocupado com o tratamento do documento, principalmente no que tange à análise do documento primário e à elaboração do documento secundário.

No tocante de seu papel documental, é preciso compreender que a Linguística Documental atua com o papel metalinguístico, portanto trata-se de compreender os processos que se aplicam para a expansão de conceitos, já que é descrição sobre descrição, ou ainda a formação de novos conceitos, consequentemente entender que verificar e investigar os reajustes e as trocas, incluindo as características semânticas envolvidas que perpassam pelo 
fenômeno de uma análise de uma linguagem natural através de uma linguagem especializada.

Sendo assim, trata-se de uma "metalinguística documental", já que se aplica a linguagem para verificar outro tipo de linguagem, no caso, outro tipo de aplicação da linguagem (GARCÍA GUTIÉRREZ, 1984, p. 138, tradução nossa). Por conseguinte,

Às vezes, a metalinguagem e a linguagem como objeto se coincidem, e concretamente em Linguística Documental usaremos termos para definir e estruturar as próprias linguagens documentais como, por exemplo, aqueles relacionados à Documentação científica. (GARCIA GUTIÉRREZ, 1984, p. 138, tradução nossa).

Nessa perspectiva, a aplicação da Linguística Documental, no tratamento e análise dos documentos, ganha dimensões metalinguísticas, pois a linguagem se torna mecanismo de controle e representação, visto que é preciso destacar que "A normalização deve ser aplicada a todos os âmbitos da atividade humana que necessita regulação.” (GARCÍA GUTIÉRREZ, 1984, p. 19, tradução nossa). O desenvolvimento humano, assim como o conhecimento acumulado pela humanidade, evidencia-se através de documentos, por isso os "[...] conhecimentos que obviamente estão fixados em alguns suportes como papel, fotografia, disco etc.” (GARCÍA GUTIÉRREZ, 1984, p. 19-20, tradução nossa).

Essa organização documental exige normas para padronizar o sistema de armazenamento e recuperação, entretanto a linguagem atua como meio de análise, de extração, de representação, de elaboração terminológica, assim como de elaboração documental e, por fim, de recuperação. A linguagem descreve e potencializa a significação do suporte, como objeto sígnico e veículo informacional, como ainda a linguagem evidencia a informatividade e significação do conteúdo.

O controle da informação através da Linguagem Documental é fundamental para garantir que o material científico seja difundido de forma organizada, para tanto a normalização da linguagem prevê a entrega de serviços eficazes para garantir intercâmbios documentais. A produção da documentação secundária requer um tratamento bastante específico a fim de representar a documentação primária, além de estabelecer parâmetros para recuperá-la. 
Desse modo, entende-se que a Linguagem Documental se destina à elaboração da documentação secundária, enquanto a documentação primária requer práticas da Documentação, a relação entre as duas se configura através de procedimentos aplicados pela análise documental, já que a "[...] chamada Difusão Seletiva da Informação necessita de uma sistematização estrita em análises anterior, para facilitar a posterior manipulação de dados e localização de documentos originais.” (GARCÍA GUTIÉRREZ, 1984, p. 22, tradução nossa).

Diante do fato de que o processo documental tornou-se algo muito importante nos estudos na Espanha, para haver o tratamento adequado, entendese que, primeiramente, deveria estabelecer a normalização dos documentos e, dessa maneira, estabelecer uma terminologia científica normalizada; por outro viés, há também a preocupação com a extração de conceitos e termos, o que se caracterizou, na Espanha, como análise documental, "[...] objeto de delimitar os conceitos que serão utilizados, analisando também as fases que, de acordo com os posicionamentos mais gerais, poderíamos denominar de descrição física e característica dos documentos." (GARCÍA GUTIÉRREZ, 1984, p. 75, tradução nossa).

Essa aproximação com a linguagem evidencia a importância da análise documental - técnica importante de tratamento da informação do documento, tem como princípio a investigação a fim de extrair da informação coletada conceitos para garantir o armazenamento, a representação e a indexação dos documentos.

Sua função de "extrair os conceitos presentes no documento", obtém o aparato da linguagem, a partir da relação terminológica que indicava a composição do campo científico, já que a principal contribuição da linguagem nesse processo era a relação semântica entre os termos. Ademais, entende-se que a análise documental atua como "Investigação técnica com a finalidade de descrição objetiva, sistemática e qualitativa do conteúdo evidente de uma comunicação.” (GARCÍA GUTIÉRREZ, 1984, p. 80, tradução nossa).

Destarte, reconhece-se a relação do tratamento documental, no processo de extração e representação, com a linguagem, pois esse procedimento deve ser realizado à base de uma terminologia especializada. Sendo assim, deve-se 
considerar "[...] a comunicação como documento, com todas as características que este comporta, a investigação técnica com a finalidade descritiva é o objetivo da análise documental." (GARCÍA GUTIÉRREZ, 1984, p. 80, tradução nossa).

Frente a essa perspectiva, "[...] o trabalho científico destina certos aparatos para esclarecer ou oferecer uma adequada direção dos termos e conceitos que são utilizados." (GARCÍA GUTIÉRREZ, 1984, p. 63, tradução nossa), assim entende-se que García Gutiérrez e Izquierdo Arroyo desenvolvem, na Espanha, estudos para direcionar a Linguística Documental como aparato para sistematizar a linguagem documental aplicada no tratamento e análise do documento primário, assim como a elaboração do documento secundário.

A relação entre a análise documental e a Linguística Documental destaca que o tratamento, a análise e a indexação realizada por dois indivíduos não terão como resultados o mesmo produto, porém, devido às questões técnicas, éticas e procedimentais, é possível chegar a um resultado similar.

Diante disso, entende-se que o trabalho com a linguagem requer precisão, por isso a preocupação com a normalização, todavia também é preciso ter cautela na extração da significação e informatividade desse conteúdo, por isso é válido destacar o "perigo real da interpretação na análise", pois pode causar "[...] graves prejuízos na hora de recuperar a informação ou de obter dados confiáveis [...]" (GARCÍA GUTIÉRREZ, 1984, p. 89, tradução nossa).

Sendo assim, a Linguística Documental pode oferecer caminhos de análise, pois "[...] a interpretação nem sempre tem uma causa cultural ou psicológica, já que, por exemplo, em nível de profundidade requerido na análise, conscientemente, provoca alterações nos resultados, sendo este um motivo objetivo." (GARCÍA GUTIÉRREZ, 1984, p. 89, tradução nossa).

Para que exista documento, é preciso ter linguagem, pois é esta que promove a "ação e a percepção intelectual", tendo em vista que se pode estabelecer que "Antes da aparição do homem existia no mundo uma infinidade de informações em potencial, existiam na espera de serem captadas." (GARCÍA GUTIÉRREZ, 1984, p. 32-33, tradução nossa), mas a transformação dessa potencialidade em informação ocorreu graças ao desenvolvimento da 
linguagem, na qual há o desenvolvimento de signos, por conseguinte a sistematização da significação e da informação.

Assim sendo, destaca-se a importância de teorias da linguagem também para o tratamento da informação veiculada nos documentos, assim como entender a importância da Linguística Documental para a evolução das técnicas de tratamento e análise documental, pois é preciso entender os processos de significação e correlação semântica da linguagem para aplicar as técnicas de leitura e interpretação para a extração da informação, assim como a relação adequada com a linguagem documental para sua representação.

Portanto, há um processo metalinguístico nos procedimentos que envolvem a interpretação da informação e sua organização em conceitos, assim como há um procedimento metalinguístico na representação, por via de uma tradução de conceitos responsáveis por representar a informação documental, já que essa informação é produzida em linguagem natural e, por conseguinte, traduzida, em procedimentos metalinguísticos, para a linguagem documental especializada.

\section{Semiótica documental na Espanha}

Com os estudos sobre a Documentação alinhados à análise documental, sendo esta relacionada ao tratamento da linguagem documental, há um avanço significativo teórico-científico, introduzindo, aos estudos sobre o tratamento documental, pesquisas vinculadas à Linguística Estrutural. Sendo assim, os estudiosos espanhóis, García Gutiérrez e Izquierdo Arroyo entendem a importância de transformar a Linguística Documental em disciplina.

A existência de um projeto docente no contexto acadêmico permitiu o desenvolvimento de trabalhos universitários direcionados aos Estudos de Biblioteconomia e Documentação, à base de elaboração de artigos e livros que deram condições de oficializar a disciplina Linguística Documental através da resolução 536/1989, de 5 de dezembro de 1988, em que se homologou um plano de estudo na Universidad de Murcia em Biblioteconomia e Documentação (IZQUIERDO ARROYO, 1990).

O principal objetivo da disciplina era "Exposição das técnicas de catalogação de todo tipo de documento desde o enfoque convencional e 
informático. Teoria da classificação e construção de tesauros.", as atividades envolvidas à matéria ainda contavam com "Análise de conteúdo dos documentos e metodologia de resumo científico", divididos em dez créditos para Análise Documental, dez créditos para Linguística Documental I e cinco créditos para Linguística Documental II (IZQUIERDO ARROYO, 1990, p. 3, tradução nossa). Esse movimento ficou conhecido como "marco acadêmico", diante do qual se desenvolvia a concepção científica e didática da disciplina, obrigando a elaboração de um programa efetivo, encabeçado pelo professor Izquierdo Arroyo (1990).

É, diante desse fenômeno histórico-científico, que se estabelece o objetivo desta seção, que se caracteriza em analisar as motivações instauradas no chamado marco acadêmico, para que Izquierdo Arroyo propusesse a Semiótica Documental. Diante disso, também se torna objetivo analisar a base teórica fundamental para a elaboração da disciplina: a Semiótica, campo de estudo desenvolvido por C. S. Peirce (2017), sob a qual há inovações apresentadas por C. W. Morris (1976). Ademais, é necessário debater as inovações propostas por essa disciplina para o aprimoramento das práticas profissionais na representação das informações extraídas do documento.

A proposta acerca da disciplina surge diante da sistematização de disciplinas que pudessem subsidiar a análise documental e, assim, estabelecer a busca de novas técnicas e de novas teorias que pudessem dialogar e fundamentar o tratamento da linguagem aplicada na representação do documento.

Diante disso, surge a preocupação com os referidos ensinamentos dessa disciplina, porque Izquierdo Arroyo entendeu que o primeiro momento era marcado pelo estudo e pela sistematização de uma base teórica consistente, capaz de subsidiar as ações e prática acerca do tratamento documental, entretanto, por outro lado, havia a necessidade de transformar esse conhecimento em disciplina, pois era necessário ensinar os futuros profissionais a aplicar essa teoria nas atividades de sua profissão.

Sendo assim, a Linguística Documental contribui para a leitura e interpretação em função análoga aos conteúdos da catalogação, sendo importante para a elaboração do Plano de Estudos do Projeto Docente. Assim, estabelece-se a importância do "marco acadêmico", pois é ubíquo na "[...] 
concepção científica e didática da disciplina, e estará presente desde a elaboração do Programa até sua implantação [...]" (IZQUIERDO ARROYO, 1990, p. 12, tradução nossa).

Diante de um contexto em que a Linguística Documental se ocupa do tratamento documental, reconhece-se características de uma prática metalinguística, denominada por Izquierdo Arroyo de Linguística Documental Descritiva, a qual está intrinsecamente relacionada à Linguística Documental Geral, pois aplicar a linguagem para avaliar o valor significativo da linguagem pressupõe tratar dos objetos da Documentação.

No entanto, Izquierdo Arroyo entende que é preciso propor para a disciplina uma denominação mais abrangente de seus propósitos, devido a isso, é proposto denominar de Semiótica Documental, sob a justificativa de que essa terminologia é mais ajustada, já que se trata da "especificação disciplinar da Semiótica geral", sendo entendida como ciência que estuda a semiose documental (IZQUIERDO ARROYO, 1990, p. 65, tradução nossa).

Segundo C. Morris (1976, p. 5), "A ciência e os signos estão indissoluvelmente ligados, pois a ciência oferece aos homens, por um lado, signos mais fiáveis e, por outro, insere os resultados obtidos em sistemas de signos.".

Essa concepção é ainda confirmada pelo princípio de que a Semiótica é a ciência que estuda o signo em vários estágios de concepção, e é a partir da tricotomia diagramática do signo que é processada a semiose, sendo assim se adequa de melhor forma às relações de significação produzidas no tratamento documental. Dessa forma, confirma-se que "À medida em que a Semiótica se ocupa do estudo de quaisquer processos de semiose (e não só unicamente dos processos que enfoca a Linguística), a presença desse termo na expressão Semiótica Documental parece mais acertada.” (IZQUIERDO ARROYO, 1990, p. 65 , tradução nossa).

O desenvolvimento da disciplina respeita os princípios teóricos direcionados à preocupação que circunda o documento, já que este é material rico e gerador de informações, das quais são constituídos os conhecimentos, todavia é a linguagem o instrumento de mediação entre a informação 
documental e a significação do receptor dessa informação, sob o qual se caracteriza o conhecimento e sua organização.

Sob essa perspectiva, Izquierdo Arroyo detecta a necessidade em discutir o processo de semiose documental, contudo há ainda o processo de compreensão acerca da atuação da Linguística Documental, proposta por García Gutiérrez, fator que se comprova mesmo pela nomenclatura da matéria, já que não se propôs denominar de Semiótica Documental, mas sim Linguística Documental I e Linguística Documental II. Sendo assim, compreender o processo que sustenta os ideais por trás do Marco Acadêmico configura o entendimento dos ideais que vê na Semiótica, por conseguinte semiose, um caminho para encontrar as respostas a fim de garantir uma representação eficaz.

Diante da busca por explorar a globalidade da Linguística Documental, Izquierdo Arroyo demonstra insatisfação com a aplicação da Linguística Estrutural saussuriana e hjelmsleviana, pois o autor entende que o processo de transposição das informações do documento primário para o documento secundário ocorria através de uma tradução, porém não uma simples tradução de pensamento, mas sim uma semiose. Izquierdo Arroyo indica a importância do hábito mental tratado por C. S. Peirce e os aspectos sintáticos, semânticos e pragmáticos tratados por C. W. Morris. Sendo assim, o autor espanhol defende a ideia de uma semiose documental.

Dessa forma, os estudos produzidos por Izquierdo Arroyo acerca da semiose documental e da presença do hábito mental para o tratamento e representação do documento é de fundamental consistência para a formulação da Linguística Documental e, principalmente, para compreender as contribuições e inovações da Semiótica Documental.

A Semiótica Documentária tem condições de estabelecer uma prática normalizadora, pois o resultado dessa análise é uma semiose documental, fator que estabelece o estágio de significação do signo que será efetivado como terminologia, por isso há a relação interdisciplinar com as teorias de Peirce e mais acentuadamente com as de Morris, pois este apresenta uma proposta de análise semiótica sob três fases: a pragmática, a semântica e a sintática, fatores que garantem, conforme Izquierdo Arroyo (1990, tradução nossa), o bom tratamento do objeto terminológico. 
Sendo assim, a aplicação da Semiótica garante, como prevê Izquierdo Arroyo, uma normalização na linguagem documental especializada, já que o conjunto de signo se revela de forma lógica em busca da unificação das ciências, assim como prática para estabelecer a significação dos conceitos extraídos do documento primário e sua adequada tradução para um documento secundário. C. Morris ainda afirma que "A Semiótica tem uma dupla relação com as ciências: ela é simultaneamente uma ciência entre as ciências e um instrumento das ciências." (MORRIS, 1976, p. 5).

Ademais, semiose pode ser entendida como processo, "numa tradição que já vem dos gregos”, sua atuação envolve três ou quatro fatores: “[...] aquilo que atua como signo, aquilo a que o signo se refere, e o efeito sobre um intérprete em virtude do qual a coisa em questão é um signo para esse intérprete." (MORRIS, 1976. p. 7).

Outrossim, Peirce define que semiose é "Toda ação dinâmica, ou ação de força bruta, física ou psíquica, ou tem lugar entre dois sujeitos que reajam igualmente um sobre o outro [...]" (SILVEIRA, 2007, p. 34). Peirce também destaca a cooperação na constituição de uma ação ou influência de três elementos a que ele se refere como sujeitos: "[...] um signo, seu objeto, e seu interpretante, essa tríplice relativa influência não sendo de modo algum resolúvel em ações entre pares.” (SILVEIRA, 2007, p. 34).

Esses três componentes da semiose, na teoria proposta por C. Morris são denominados de "veículo sígnico, o designatum e o interpretante", sob essa teoria há um quarto fator, o qual o semioticista reconhece como intérprete. Esclarecer esses conceitos são importantes para compreender a relação que possuem com o processo de semiose e, por conseguinte como atuam nas disposições sintáticas, semânticas e pragmáticas na semiótica de Morris. Assim, “[...] a semiose é um dar-se-conta-mediato. Os mediadores são os veículos sígnicos; os dar-se-conta-de são os interpretantes; os agentes do processo são os intérpretes; aquilo que se dá conta são os designata." (MORRIS, 1976, p. 7).

Sendo assim, é a relação triádica da semiose que efetua a relação definida como a "dimensão semântica da semiose", cujo objeto são as "relações de signos aos objetos a que os signos se aplicam", assim como a relação dos signos aos interpretantes será chamada de "dimensão pragmática da semiose" 
(MORRIS, 1976, p. 10). Por fim, a terceira dimensão será denominada de "dimensão sintática da semiose", cujo objeto é a relação que os signos estabelecem com outros signos, já que “[...] potencialmente, se não efetivamente, cada signo tem relações com outros signos [...]" (MORRIS, 1976, p. 10).

A contribuição para sistematizar a linguagem documental aplicada na representação do documento, pensando o termo aplicado como signo, é a semiose sintática que caracteriza com precisão as proposições de diversas naturezas como "analíticas, contraditórias, sintéticas e derivações" (MORRIS, 1976, p. 18), pois é nessa prática em que os termos se relacionam, seja ampliando, através da formulação da frase, seus predicativos, seja delimitando as possibilidades de conexão em uma rede semântica.

Além disso, a coordenação dos descritores é orientada pela distinção de "signos lógicos e descritivos", sendo passível a definição precisa de "signos sinônimos e proposições equivalentes", além de serem aplicados a fim de "[...] caracterizar o conteúdo de uma proposição, ocupar-se dos paradoxos lógicos, classificar certos tipos de expressões e clarificar as expressões da necessidade, possibilidade e impossibilidade." (MORRIS, 1976, p. 18).

Ao tratar da dimensão semântica da semiose, é preciso entender que se estabelece relação dos signos com "os objetos que denotam ou possam denotar" (MORRIS, 1976, p. 25). A Semântica é o núcleo da problemática que envolve a análise documental e a aplicação da linguagem documental, pois essa relação é fundamental para garantir o valor do documento no processo de tratamento, extração e indexação da informação. Provavelmente, por isso que, para Izquierdo Arroyo, a semiose semântica era a essência da ciência da Documentação.

Por fim, a dimensão pragmática da semiose, que consiste na "relação entre os signos e os seus utilizadores", fato que direciona a importância dessa semiose para a "compreensão das atividades intelectuais" (MORRIS, 1976, p. 32). Assim, como aponta Morris, pragmática “[...] designa-se a ciência da relação dos signos aos seus intérpretes.”, e é esse fator que Izquierdo Arroyo aponta em seus estudos, já que faz alusão ao tratamento documental (MORRIS, 1976, p. 32). 


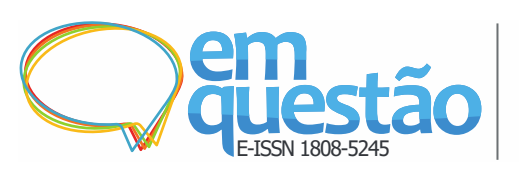

Assim,

[...] a maior parte dos signos, senão todos, têm como intérpretes organismos vivos, é uma caracterização suficientemente cuidadosa de dizer que ela trata os aspectos biótipos da semiose, isto é, todos os fenômenos psicológicos, biológicos e sociológicos que ocorrem no funcionamento dos signos. (MORRIS, 1976, p. 32).

Esses procedimentos preveem aquilo que o professor espanhol nomeou como "hábitos operativos cognitivos, de caráter especulativo e prático" (IZQUIERDO ARROYO, 1990, p. 79, tradução nossa). Devido a isso, pensando na estrutura da disciplina, há a insistência da execução de exercícios práticos a fim de garantir a experiência para que se crie "hábitos e automatismos", pois “[...] quando os atos repetidos se realizam com rigor e método efetivos, as habilidades resultantes já são experiências.” (IZQUIERDO ARROYO, 1990, p. 79, tradução nossa). Dessa maneira, a experiência com "exercícios de tratamento linguístico-documental" proporcionará conhecimento acerca da "atividade racional científico-técnica" (IZQUIERDO ARROYO, 1990, p. 79, tradução nossa).

Nessa linha, na consolidação da disciplina, os exercícios práticos preveem o processo de interiorização de novos esquemas de conduta profissional, a qual se consiste em uma "[...] ampliação e potencialização do espírito analítico derivado da experiência cotidiana." (IZQUIERDO ARROYO, 1990, p. 79, tradução nossa). Essas habilidades são decorrentes da semiose pragmática, pois se efetua a partir do contado do intérprete com designatum, consequentemente, com o designata.

Ademais, a internalização da experiência efetiva o controle adequado dos procedimentos profissionais, porque o "hábito epistemológico apropriado se traduzirá na aquisição de novos esquemas de conduta", além disso a repetição de exercícios é o instrumento para formalizar essa habilidade, visto que "Esses esquemas apenas se adquirem através de estudos sistematizados da linguagem documental e se tornam hábitos com a prática adequada da teoria." (IZQUIERDO ARROYO, 1990, p. 79, tradução nossa).

Destarte, atendem às expectativas da Documentação mencionada por López Yepes, Garcia Gutiérrez e Izquierdo Arroyo no processo de tratamento e indexação, pois a Semiótica aplicando a semântica e a pragmática no processo 
de semiose, juntamente com a sintaxe, encontra uma metodologia para proceder a análise documental em suas esferas de tratamento documental e extração de informação devido à aplicação dos signos em processo de reconhecimento da semiose.

Esses fatores podem ser aplicados aos objetos informacionais e direcionar o processo de indexação, através de uma normalização de semiose, garantindo, assim, a devida aplicação da linguagem documental, que interfere na organização e representação do conhecimento e da informação, por conseguinte contempla às prerrogativas teóricas, práticas e metodológicas da Ciência da Informação. 


\section{Considerações finais}

A produção de estudos na Espanha acerca da Documentação e principalmente sobre meios de tratamento e análise documental ofereceu ao campo da Documentação e, por conseguinte a toda área da Organização do Conhecimento duas disciplinas fundamentais para o tratamento documental: Linguística Documental e Semiótica Documental.

Bem apresentado nesta pesquisa, ficou evidente a importância do documento para registrar e provar as atividades humanas, assim como os aspectos inerentes para organizar o conhecimento, como ainda seu armazenamento, indexação e recuperação. Dessa forma, a linguagem documental é recurso importante para garantir a representação e o processo comunicacional que envolve a representação sistematizada, a indexação e a recuperação, mais precisamente.

Evidentemente, a linguagem é instrumento cabal para realização das atividades profissionais que envolvam o tratamento e análise documental, bem como sua representação. Dessa forma, os trabalhos espanhóis, encabeçados por López Yepes, García Gutiérrez e Izquierdo Arroyo legitimam não apenas as contribuições francesas acerca da linguagem documental especializada, mas ampliam as discussões sobre a linguagem ao inovarem o tratamento, estabelecendo diálogos entre a Documentação e a Linguística Estrutural e a Semiótica.

É sob essa perspectiva que os trabalhos espanhóis ganham importância, pois é evidente que o processo de tratamento, de análise e de representação não pode ser minimizado em apenas extrair conceitos e representá-los através de linguagem documental especializada. É preciso, efetivamente, que haja a leitura, análise e interpretação, fatores que requerem conhecimentos técnicos e pessoais, pois cada indivíduo possui habilidades referentes ao seu estágio mental de compreensão da informação, tanto quanto suas atribuições profissionais.

Sendo assim, a Linguística Documental evidencia a necessidade de estudos acerca da metalinguística documental, pois esse processo requer um tratamento específico fundamentado pelas teorias da Linguística, que envolvem a análise e a interpretação para a extração das informações do documento, e o 
processo de significação para a representação dessas informações na elaboração de um documento secundário.

Assim, os aspectos epistemológicos que envolvem essa disciplina requerem a continuidade de estudos a fim de explorar a potencialidade teórica que a Linguística tem a contribuir, não somente a Linguística Estrutural, mas é preciso que explore a Teoria da Enunciação, a Análise do Discurso, a Pragmática, a Linguística Textual, os aspectos da Morfologia que envolvem a Filologia, Etimologia e a Lexicologia a fim de propor inovações para a área, visto que a informatividade vai além daquilo que está escrito.

Ademais, este estudo também evidenciou a importância da Semiótica para o desenvolvimento das técnicas de tratamento e representação das informações documentais, já que, como evidenciou Izquierdo Arroyo, há um processo mental que envolve a tradução do documento original em um documento secundário, ou seja, há um fenômeno inerente ao hábito mental, denominado de semiose documental, que precisa ser estudado a fim de garantir a boa prática na representação. Sendo assim, também se entenderam serem necessários mais estudos nesta linha a fim de contribuir para a área.

Por fim, evidenciaram-se os avanços apresentados nesses estudos que exploram teorias da linguagem para proceder as práticas de tratamento documental inerentes à Organização do Conhecimento e à Ciência da Documentação, os quais reconhecem a linguagem como elemento fundamental para se alcançar a devida interpretação do conteúdo temático, assim como aspectos para orientar a descrição, representação e indexação tanto pela semiose, como também pelo hábito mental.

Devido a isso, é evidente a preocupação atual com a análise documental, terminologia e linguagem documental, todavia esses processos de representação estão limitados aos mecanismos escritos. Sendo assim, é com a Linguística, e somente através dela, que será possível extrair do documento informações que estão subentendidas e inscritas em seus aspectos dialógicos, em uma perspectiva intertextual, o chamado signo documental. Na mesma medida, é com a Semiótica, e somente através dela, que será possível tratar a semiose documental. 
Portanto, as contribuições dos estudos sobre Documentação na Espanha foram fundamentais para o avanço da área e apresentar um caminho para um tratamento mais complexo da informação documental. Diante disso, este trabalho teve como princípio a análise de diversos fatores epistemológicos que envolvem esse percurso a fim de contribuir para a compreensão desse movimento que surge na Espanha, referente à elaboração das disciplinas Linguística Documental e Semiótica Documental. Ademais, também proporcionou o entendimento acerca de suas atuações sobre a informação documental e, assim, vislumbra caminhos para inovações na área.

\section{Referências}

BRIET, S. O que é documentação? Trad. Maria de Nazareth Rocha Furtado. Brasília, DF: Briquet de Lemos/Livros, 2016.

BUCKLAND, M. K. What is a document? Journal Of The American Society For Information Science (JASIS), United States of America, v.48, p.804-809, 1997.

BUCKLAND, M. K., Documentality Beyond Documents. The Monist, Oxford, v. 97, n. 2, p. 179-186, 2014.

BUCKLAND, M. K. Teoria dos Documentos: Uma Introdução. UC

Berkeley. 2015. Disponível em: https://escholarship.org/uc/item/87s642x7. Acesso em: 31 out. 2021.

BUCKLAND, M. K. Document theory. Knowledge Organization, BadenBaden, v. 45, n. 5, p. 425-436, 2018

DAY, R. All that is the case: documents and Indexicality. Scire: Representación y Organización del Conocimiento, Zaragoza, v. 22, n. 1, p. 57-63, 2016.

ESTIVALS, R. A Dialética contraditória e complementar do escrito e do documento. R. Esc. Bibliotecon. UFMG, Belo Horizonte, v. 10, n. 2, p. 121-152, set. 1981.

ESTIVALS, R. Paul Otlet dans l'histoire de la bibliologie. Revue de Bibliologie: Schéma et Schématisation, Paris, n. 73, p. 35-42, 2010.

FAYET-SCRIBE, S. Vocês conhecem Suzanne Briet? In: BRIET, S. O que é documentação? Brasília: Briquet de Lemos, 2016. p. 52-64.

GARCÍA GUTIÉRREZ, A.L. Linguística documental: aplicacion a la documentación de la comunicación social. Mitre: Barcelona, Espanha, 1984.

GARCÍA GUTIÉRREZ, A.L. Teoria da la inidización: nuevas parámetros de investigación. Transinformação, Campinas, v. 1, n. 2, 1989. 
HJELMSLEV, L. Prolegômenos a uma teoria da linguagem. Trad. J. Teixeira Coelho Netto. São Paulo: Perspectiva, 2013.

IZQUIERDO ARROYO, J. M. Esquemas de linguística documental. Barcelona: Promociones y Publicaciones Universitarias, 1990.Tomo I.

IZQUIERDO ARROYO, J. M. La organización documental de Conocimiento I/1: El marco documental. Madrid: Tecnidoc, 1994.

IZQUIERDO ARROYO, J. M. Estructuras conceptuales para la representación documental. In: GARCIA MARCO, F. J. (Ed.). Actas del I Encuentro del Isko - España - Organización del conocimiento em sistemas de información y documentación. Zaragoza: Libreria General, v. 1. p. 27-50, 1995.

LARA, M. L. L. G. Conceitos de organização e representação do conhecimento na ótica das reflexões do Grupo Temma. Informação \& Informação, Londrina, v. 16, n. 2, p. 92-121, 2011.

LARA, M. L. L. G. Linguagem documentária e terminologia.

Transinformação, Campinas, v. 16, n. 3, 231-240, 2004.

LARA, M. L. L. G. Linguística Documentária: seleção de conceitos. 2009. Tese (Livre Docência em Análise Documentária). Escola de Comunicações e Artes, Universidade de São Paulo, São Paulo, 2009.

LARA, M. L. L. G. Linguagem documentária na ótica de J.-C. Gardin, in J.A.C. Guimarães, V. DODEBEI (eds.), Organização do conhecimento e diversidade cultural, Marília, ISKO-Brasil, p. 748-757, 2015.

LARA, M. L. L. G.; TÁLAMO, M. F. G. M. Uma experiência na interface linguística documentária e terminologia. DataGramaZero, João Pessoa, v. 8, n. $5,2007$.

LASSO DE LA VEGA, J. Cómo utilizar una biblioteca. Madrid: [s.n.], 1935.

LE GOFF, J. Documento/monumento. In: LE GOFF, J. História e memória.

Campinas: Ed. Unicamp, 1994.

LÓPEZ YEPES, J. La Documentacion como disciplina. Teoria e História. 2. ed. EUNSA: Navarra, Espanha, 1995.

LÓPEZ YEPES, J.; ROS GARCIA, J. ¿Qué es Documentación? Teoria e História del concepto em España. Madrid, Espanha: SÍNTESIS, 1993.

MEYRIAT, J. Document, documentation, documentologie. Schéma et Schématisation, Paris, n. 14, p. 51-63, 1981.

MEYRIAT, J. et al. Documento, documentação, documentologia. Perspectivas em Ciência da Informação, [s.l.], v. 21, n. 3, p. 240-253, set. 2016. 
MORRIS, C. W. Fundamentos da teoria dos signos. São Paulo: Livraria Eldorado Tijuca; Edusp, 1976.

MURGUIA, E. Percepções e Aproximações do Documento na Historiografia, Documentação e Ciência da Informação. InCID: Revista de Ciência da Informação e Documentação, São Paulo, v. 2, n. 2, p. 42-53, 13 dez. 2011.

NÖTH, W. A Semiótica no século XX. São Paulo: Annablume, 1996.

ORTEGA, C D; SALDANHA, G S. A noção de documento no espaço-tempo da Ciência da Informação: críticas e pragmáticas de um conceito. Perspectivas em Ciência da Informação, [s.l.], v. 24, p. 189-203, mar. 2019.

OTLET, P. Tratado da documentação: o livro sobre o livro, teria e prática. Trad. Taiguara Villela Aldabalde et al. Brasília, DF: Briquet de Lemos/Livros, 2018.

PEIRCE, C. S. Semiótica. Trad. José Teixeira Coelho Neto. 4. ed. São Paulo: Perspectiva, 2017.

RAYWARD, W. B. Visions of Xanadu: Paul Otlet (1868-1944) and hypertext. Journal of the American Society for Information Science, New York, v. 45, p. 235-250, 1994.

SAUSSURE, F. Curso de linguística geral. Trad. Bras. Antônio Chelini et al. São Paulo: Cultrix, 2006.

SILVEIRA, L. F. B. Curso de Semiótica geral. São Paulo: Quartier Latin, 2007.

TÁLAMO, M. F. G. M.; LARA, M. L. L. G. O campo da linguística

documentária. Transinformação, Campinas, v. 18, n. 3, p. 203-211, 2006.

\title{
Documental linguistics and documental semiotics: Spanish journey
}

\begin{abstract}
The purpose of this research is to analyze the epistemological process of Documental Linguistics, as well as Documental Semiotics in Spain. Added to this, he also wants to analyze the relationship of these disciplines with Documentation developed in Spain. Also, establish brief relationships with the theories that act as the basis of Documental Linguistics, in this case Structural Linguistics and Documental Semiotics, in turn, Semiotics. For that, a qualitative methodology, descriptive type, of exploratory character was applied. It is a theoretical-bibliographic approach, with a critical and reflective purpose about the disciplines of Documental Linguistics and Documental Semiotics, as well as about Structural Linguistics and Semiotics. Thus, there is a metalinguistic
\end{abstract}


process in the procedures that involve the interpretation of information and its organization into concepts and the representation of the document, through a translation of concepts responsible for representing document information, as this information is produced in natural language, therefore translated, in metalinguistic procedures, into specialized documental language. Therefore, studies that explore Knowledge Organization and Documentation Science are aligned with the importance of language in the document processing process. Thus, Linguistics makes it possible to extract from the document information that is implied and inscribed in its dialogical aspects, in an intertextual perspective, the so-called documental sign, the same measure, Peircean Semiotics makes it possible to treat documental semiosis.

Keywords: Documentary Linguistics; Documentary Semiotics; Documentation Science; Spanish documentation

Recebido em: 13/05/2021

Aceito em: 04/10/2021

\section{Declaração de autoria}

Concepção e elaboração do estudo: A. R. Martines.

Coleta de dados: A. R. Martines.

Análise e interpretação de dados: A. R. Martines; C. C. Almeida.

Redação: A. R. Martines; C. C. Almeida.

Revisão crítica do manuscrito: C. C. Almeida.

\section{Como citar:}

MARTINES, Alexandre Robson; ALMEIDA, Carlos Cândido. Linguística documental e semiótica documental: percurso espanhol. Em Questão, Porto Alegre, v. 28, n. 2, e-114032, abr./jun. 2022. https://doi.org/10.19132/18085245282.114032

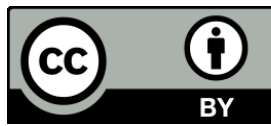

